\title{
Future Time Perspective As A Temporal Anchor: Applications To Organizations
}

Peg Thoms, (E-mail: mat6@psu.edu), Penn State, Behrend

Dawn Blasko, (E-mail: dgb6@psu.edu), Penn State, Behrend

\begin{abstract}
Future time perspective was introduced as a cognitive dynamic orientation. We propose a model explaining its relationship with personality and organizational behavior, explain results of empirical tests, and identify uses. There has been a great deal of confusion regarding the meaning and measures of Future Time Perspective. Despite being treated as a stable trait for many years, it is reemerging as a temporal anchor that affects human behavior.
\end{abstract}

\section{Introduction}

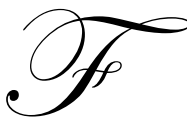

uture Time Perspective sounds like a crystal ball. If that were true, it would be wonderful for leaders and members of organizations to have a perspective on the future. In actuality, however, Future Time Perspective is probably more of an anchor than a crystal ball. Although a less romantic image, this anchor serves an important purpose in human and organizational behavior. The concept of Future Time Perspective has been in the psychology literature for a long time, but it has only recently been introduced into the organizational literature. The purpose of this paper is to explain how Future Time Perspective might affect organizational behavior through the use of a theoretical model, to provide empirical support for this model, and to explore implications for further organizational research.

Lewin (1942) defined time perspective as the totality of an individual's views of his psychological future and past existing at a given time. He specifically described future time perspective (FTP) as the present anticipation of future goals. The early literature (see Daltrey, 1982, \& Lens, 1986, for reviews) is fairly consistent in describing FTP as the inclination that a person has to plan for and act in ways that will lead to future objectives. Bergius (1957) suggested that FTP has both a motivational component and a cognitive (an expectation that the goals will be realized) component. Our day-to-day behavior is determined, in part, by our FTP (Nuttin \& Lens, 1985). This behavior could include scheduling and choice of activities, writing notes on our calendars of tasks to do in the future, planning, and imaging the future. In other words, FTP may be a key motivational force in behavior.

Lens (1986) suggests that despite high agreement among early theoretical conceptualizations of FTP as a cognitive-dynamic orientation toward future goals, over time the concept came to be used in a wide variety of ways. Psychologists, assuming that FTP was a stable characteristic of personality, often focused on individual differences among groups (for a discussion see Friedman, 1990; McGrath, 1988; Slife, 1993). For example, some researchers have focused on FTP and cultural background noting that cultures vary in the tempo with which life is lived (Levine, 1997; Spadone, 1992) whereas others have looked at gender and Socio-economic status (e.g., Lamm, Schmidt, \& Trommsdorff, 1976). A great deal of work has focused on FTP as a predictor of risky behaviors such as reckless driving, unprotected sex, and the use of alcohol and drugs (e.g., Alvos, Gregson, \& Ross, 1993; Keough, Zimbardo, \& Boyd, 1999; Zalenski, Levey-Thors, \& Schiaffinor, 1998). The general logic was that if one had low future time perspective and, therefore, was more focused on the present, that this could lead to more hedonistic and risky behaviors such as smoking, having unprotected sex, or using illicit drugs. Developmentalists have investigated how FTP varies with age. When investigated across the life span, time perspective appears to be curvilinear, short in 
early childhood long in late adolescence and early adulthood, and shortening again in old age when time perspective tends to be more present oriented (Carstensen \& Lang, 1997).

Even this work however, has focused on the more stable aspects of time perspective and neglected to consider the more dynamic aspects. We propose that future time perspective acts as a cognitive anchor point for future planning and decision-making. People may make an active cognitive assessment of the time frame that they are working within, and then use this as an anchor point for assessing relative priorities, setting specific goals and planning the activities needed to realize those goals. There has been a great deal of research on cognitive illusions such as framing effects and the anchoring and adjustment heuristics that influence decision-making and problem solving. For example, adding vivid but irrelevant context information can greatly influence decisions. Similarly, providing an anchor point for a judgment can greatly influence estimates. To take the classic demonstration, the answer to the multiplication problem $1 \times 2 \times 3 \times 4 \times 5 \times 6$ is consistently estimated to be lower than the equivalent problem 6 × $5 \times 4 \times 3 \times 2 \times 1$ (Tversky \& Kahneman, 1982). In a similar way we believe that the cognitive anchors provided by future time perspective provide a needed structural framework for the human mind.

A similar view has recently emerged within social psychology. Socioemotional selectivity theory (Carstensen, Isaacowitz, \& Charles, 1999) focuses on the setting of social goals and priorities and how it influences the development of relationships. It views FTP as a dynamic motivational variable that may change across the life span. In deciding on social goals, i.e., who to talk to or reach out to, whom to associate with etc., people first make a cognitive assessment of the time frame. If the time frame is long, then we are more likely to focus on knowledgerelated goals and take the risk to reach out to those that we do not know very well, but who might provide the requisite knowledge. On the other hand, if the time frame is shorter, we may choose to spend time with those who are closer to us, and we will prioritize our more emotional goals. This explains why as people get older and near the end of their lives, they often show a shift towards a more present time orientation and, have as a primary goal, building or rebuilding close relationships.

We are suggesting that a similar process occurs at a more micro level each time we are faced with a new project or activity. We actively envision the future goal in our mind's eye and then assess the time frame. If our perception of the future is long, we are more likely to set knowledge-related long term goals. We may be less risk aversive and willing to try new strategies. On the other hand, if our anchor point is short, we may need to be more present oriented, and more risk aversive, giving higher priorities to sub-goals that provide more immediate benefits. Thoms and Greenberger (1995) have called this process temporal attunement and have suggested that it is an important aspect of successful leadership.

Despite the obvious relevance to organizational research, few studies in the field have explored this useful construct. This neglect is due, in part, to the ambiguity of various definitions of FTP, to the difficulty of operationalizing and measuring FTP, and to the lack of a coherent theory of FTP as it relates to organizational behavior. This paper will address the first and third issues and provide some guidance to scientists regarding measurement tools that have been used in organizational research.

\section{Future Time Perspective in the Organizational Behavior Literature}

Jaques' $(1976,1982)$ Stratified Systems Theory utilizes future time-frame ranges (i.e. how far into the future one is capable of thinking) to define stratified cognitive states. He found that these states relate to increasing cognitive power, work capacity, hierarchical level and perceptions of fair pay. This theory has been applied to entrepreneurship (Bucy, 1987) and organizational design (Burke, 1986). Other studies have linked individual time perspective to intuitive thinking, planning behavior, envisioning, environmental sensing, and achievement orientation (Bluedorn, 1986; Clark, 1985; Goodman, 1975; Knapp \& Garbutt, 1958; Mann, Siegler \& Osmond, 1968). Das' $(1986,1991)$ research has found a link between a leader's future orientation and strategic planning. Weick (1979) described planning behavior as future perfect thinking.

Recently, there has been some research in the field of organizational behavior specifically examining FTP and its relationship to leadership vision. Using Bird and Jordan's (1988) measure, Thoms and Greenberger (1998) 
found a significant correlation $(\mathrm{r}=.47, \mathrm{p}<.01)$ between FTP and pre-training visioning ability in a vision training research study. Following training, the correlation between FTP and post-training visioning ability went up to $.60(\mathrm{p}$ $<.01)$. Visioning ability also rose significantly. The research was done with 120 business managers enrolled in seminars on leadership visioning. In a test of the content validity of their visioning ability scale, Thoms and Blasko (1999) found a significant relationship between FTP and visioning ability using 14 items from Daltrey's (1982) measure of FTP. The participants were 170 college students enrolled in introductory business and psychology classes and 411 college leaders taking part in a week-long nationally-known leadership program. No other research specifically examining FTP could be found that was published in the organizational behavior literature.

\section{Measurement of Future Time Perspective}

Over 100 methods have been designed and used to measure temporal orientation (Vella, 1977). These instruments are of limited value to organizational research for several reasons. According to Bird and Jordan (1988), the first problem is a lack of consensus among researchers on what core dimensions make up temporal attitudes, perspectives and behavior. They also note that paper and pencil instruments have had questionable reliability and, as a result, questionable validity. Lens (1986) suggests that the operationalization of FTP over time has diverted it from being used as a motivational state to its conceptualization as a personality trait.

The various methods of measuring FTP range from paper-and-pencil tests to tell-me-a-story techniques. For a complete review of the various techniques, see Wallace and Rabin (1960) or Nuttin, Lens, Van Calster, and De Volder (1979). Most of these techniques would be very difficult to use in organizational research. For example, one of the tell-me-a-story techniques is The Future Events Test (Wallace, 1956). With this test, subjects are asked to list a number of events that they expect to experience in the future (Lens, 1986). They are then asked to indicate how old they will be at the time that the event will happen. The mean of the differences between the present age of the subject and the ages predicted are used as the FTP-extension score. Another technique is Nuttin's Motivational Induction Method (MIM) that is more closely related to the conceptualization of FTP as a cognitive-motivational variable (Nuttin \& Lens, 1985). Subjects are asked to formulate a personal goal that comes to their minds when reading a sentence beginning like "I strive to...". Two types of scoring are merged. The first analyzes the motivational content of the goal and the second places the goal on a temporal scale.

Daltrey (1982; Daltrey \& Langer, 1984) attempted to develop a pencil-and-paper test that would eliminate some of the concerns regarding psychometric properties raised by Vella (1977) in his review of the measures of FTP. She developed an 80-item instrument that showed FTP to be a unitary factor. Bird and Jordan (1988) designed a paper-and-pencil instrument that also addressed Vella's (1977) concerns. Using Daltrey's scale as a model, they developed a 30-item measure which, according to their analysis, had five factors: Pessimism (the degree of anxiety and negative affect regarding the future), Intention (the extent of conscious projection of action and events into the future), Pace (the amount of speed at which one perceives time moving), Optimism (the degree of hopefulness and positive affect regarding the future), and Density (the amount of activity one anticipates in the future). Bird and Jordan's instrument used wording appropriate for organizational managers and is considerably shorter than Daltrey's scale making it easier to administer when working with business professionals. The internal consistency reliability was high (alpha $=.92$ ).

\section{Proposed Model of FTP as a Temporal Anchor}

In their model of the relationship between leadership and time orientation, Thoms and Greenberger (1995) suggested that FTP, along with other aspects of one's temporal alignment (which they defined as internal biases about time), would influence one's ability to create an organizational vision, as well as to make accurate predictions about the future of an organization, recapture the past, and warp time (i.e. cognitively project oneself and an organization into a future environment). Recent research has provided some empirical support for parts of that model (Thoms \& Greenberger, 1998; Thoms \& Blasko, 1999). Temporal anchor theory builds on earlier work and extends beyond leadership to behavior at all levels of an organization. We are suggesting that FTP involves both relatively stable and more situation-specific aspects. The more stable aspects of FTP include developmental shifts across the life span and differences based on the major dimensions of personality. These aspects will have 
contributions from both genetic and cultural factors. For example, a person may be more likely to have high FTP if they are more open to new experiences, more socially extroverted and show less daily worry and anxiety. If an individual grows up in a culture which is very future oriented, then these characteristics will be supported and encouraged, whereas in a culture which is more focused toward the present or past, an individual's FTP will be decreased (although it may still be high, relative to peers).

We all have an ultimate temporal anchor point framed by a finite lifespan. However, for most working age adults, we focus the majority of our attention within a future time frame that varies from weeks to months to years. We need to be able to hold in long-term memory the details of many overlapping projects within that larger temporal framework. Just as we build rooms within a house and anchor the walls to the same foundation, a manager in an organization may need to maintain a complex cognitive structure of several projects at different stages of completion (Thoms \& Pinto, 1999). If the manager is allocating their limited resources to the appropriate future goals within the corporate framework, then we can say they have achieved temporal attunement (Thoms \& Greenberger, 1995).

Of course, it requires both adequate working memory capacity and considerable cognitive adaptability to manipulate our attentional focus from one time perspective to another. For example, a person planning a new facility that will open in 12 months must be able to switch between that time span and day-to-day operational decisions. These temporal structures of our lives are largely unconscious and are usually brought into conscious awareness only when we are primed by an important life event such as a marriage, birth or death, or in our work life, by beginning a new job, getting a promotion, or beginning or completing a major initiative. Yet, although largely unnoticed in everyday life, we would argue that our future time perspective provides a cognitive structure, or anchor, in the mind that is critical to human motivation. When we volitionally orient our attention to envision the future, we set an anchor that provides a reference point for further reasoning and decision-making. If the time span we envision is perceived as expansive, then we may prioritize goals that require more risk and more resources. If the future is seen as more limited, as when we are close to retirement, or when a firm project deadline is approaching, then risk will be perceived as more aversive. To expand on the views of Carstensen, Isaacowitz, and Charles (1999), one will tend to focus more on trusted colleagues and current knowledge. Note that this prioritization of goals will depend less on actual time frame (e.g. six months) than on our own individual perception of time frame. One person may see six months as far in the future, whereas another may see it as a very brief period of time. Obviously, if coworkers on a team are on opposite ends of this dimension, then difficulties may arise.

Envisioning the future provides one with a way to contact and elaborate on these usually unconscious temporal cognitive structures, so that we can explore appropriate sub-goals and to plan concrete strategies to move closer to the end goal. In cognitive and sports psychology this process of envisioning has been called mental simulation or mental rehearsal and it has been shown to improve both physical performance, as in a diver visualizing their perfect dive (e.g. the 2000 gold medal winning diver who used visualization in place of practice while injured), as well as performance in more intellectual tasks. This type of visioning may be highly motivational because it makes the process of moving toward the future goal much more concrete. In the minds' eye, we can see the future and watch ourselves move toward the goal. This makes reaching the goal seem less overwhelming as we focus on accomplishing a single small step of the project (sub-goal) rather than taking on the whole project at once (Thoms \& Govekar, 1997).

Visioning also makes our estimates of the time needed to complete a project much more accurate. We all fall pray to a well-known self-regulatory dysfunction called the planning fallacy (Kahneman \& Tversky, 1979). The planning fallacy refers to the way in which we inevitably underestimate both the time and the resources needed to adequately complete a future complex project. Take, for example, the Chunnel connecting England and France and the new Denver airport. Both went millions of dollars over budget and took much longer to complete than expected. 
Cognitively the planning fallacy is similar to one of the earliest studied perceptual illusions (Oppel-Kundt illusion cited in Coren \& Girgus, 1978). For example, take the two lines below.

A)

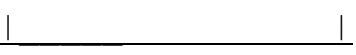

B)

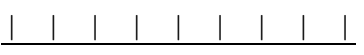

Most people estimate the horizontal line A) as shorter than line B). Line B is filled with more intervening information. Similarly, if we think of a project as one large step then we may estimate the time it takes to complete this one large step as considerably less than the time is takes to complete the 9 smaller steps that lead to the goal. When we use visioning processes we can fill in the missing steps towards the future goal, thereby making each step more manageable and increasing our estimates of time to project completion to a more realistic level. This suggests that visioning will only be an effective tool if the mental simulation includes not just reaching the goal but also simulating the process of getting there (Taylor, Pham, Rivkin, \& Amor, 1998).

Research has suggested that mental simulations are not always effective (Richardson, 1994). First they require the ability to create and control vivid mental imagery, second they require the ability to perceive the future optimistically (Thoms \& Blasko, 1999). If we attribute our failure as internal, stable and global then it is unlikely that we will see any value to future planning. Rather, it is important to feel that we have some control over our future. We must believe that we deserve some credit for the positive events that occur in our lives and believe that negative events can be changed. Research has shown that optimistic individuals are less susceptible to depression, and more successful in a variety of jobs, in large part because they are more persistent in the face of negative consequences (Seligman, 1990).

In the organizational literature much has been written about leadership vision and visionary leaders are often seen as those who have high FTP, but our analysis suggests that if one only looks to the future, problems can arise. Rather, leaders as well as workers in an organization must be flexible enough to meet the demands of the situation. They will need to have the cognitive skills to reach temporal attunement. Leaders of large organizations also need the cognitive capacity to maintain multiple temporal representations and to switch rapidly between them as the need arises (Bluedorn, Kaufman, \& Lane, 1992).

Figure 1 shows the model of FTP as a Temporal Anchor between personality dimensions and organizational skills and behavior that relate to time and motivation. It also suggests linkages between FTP and organizational behavior. The + and - signs indicate the proposed direction of the relationship of each variable with FTP. FTP is part of a process that leads to increased motivation for individuals and for leaders who use visioning. This relates to FTP's original conceptualization as a dynamic cognitive variable, rather than merely as a stable personality construct.

Our model predicts that FTP will be more likely in certain types of personalities, however, little research has focused on this issue. Recently, organizational scientists have begun to use the Big Five personality model, which suggests that the majority of personality traits can be categorized under one of five basic factors. The Big Five model of personality has been supported by extensive psychometric analyses (Barrick \& Mount, 1991; Barrick \& Mount, 1993; Goldberg, 1990; McCrae \& John, 1992) and has been shown to be useful across cultures (McCrae \& Costa, 1997; Pulver, Allik, Pulkkinen, \& Hamalainen, 1995; Salgado, 1997) and to be relatively stable over time (Costa \& McCrae, 1992). In a review of research on vocational behavior, Conscientiousness (positively), Extraversion (positively), and Neuroticism (negatively) were most frequently associated with successful vocational behavior (Tokar, Fischer, \& Subich, 1998). Judge, Higgins, Thoresen, and Barrick (1999) found that Conscientiousness predicted intrinsic and extrinsic career success and that low Neuroticism predicted extrinsic success.

The five factors are Conscientiousness, Extraversion, Neuroticism, Agreeableness, and Openness to Experience. A conscientious person is likely to be dependable, careful, responsible, organized, hard working, 
persistent, and achievement-oriented. Both persistence and achievement oriented infer a future orientation. We expect that people high in Conscientiousness will be higher in FTP.

Hypothesis 1: There is a positive relationship between Conscientiousness and FTP.

Extroverted people would be described as sociable, gregarious, assertive, talkative, energetic, and active. We are predicting that extroverted people will be more future-oriented than people who are low on this dimension.

Hypothesis 2: There is a positive relationship between Extroversion and FTP.

People who score higher on the neuroticism scale would be characterized as emotionally unstable, unable to adjust, pessimistic, self-conscious, anxious, depressed, angry, embarrassed, emotional, and insecure. This suggests a more negative approach to life. Since positivism is correlated with FTP (Thoms \& Greenberger, 1998), we would expect the opposite would be true with high Neuroticism.

Hypothesis 3: There is a negative relationship between Neuroticism and FTP.

Agreeable people are considered courteous, flexible, trusting, good-natured, cooperative, forgiving, softhearted, and tolerant. Agreeableness indicates a more positive approach to other people and positivism has been shown to relate to FTP. We expect that agreeable people will be more future-oriented than those who are not.

Hypothesis 4: There is a positive relationship between Agreeableness and FTP.

Those who are open to experience would be intelligent, imaginative, curious, original, open-minded, and artistic. We expect that those who are open will be more future oriented than people who are not open to new experience since new experiences are often anticipated as future events.

Hypothesis 5: There is a positive relationship between Open to Experience and FTP.

The second purpose of this study was to explore the relationship between FTP and other variables that are important to work motivation. These are variables that, like FTP, may vary depending on the situation and past experiences. Specifically, we looked at workers' Need for Achievement, Locus of Control and Self-Esteem. Need for Achievement suggests that a person would set goals, and would persist toward the goals. Goal setting and persistence toward goals relate to the future, therefore we expect that:

Hypothesis 6: There is a positive relationship between Need for Achievement and FTP.

Locus of Control is an indication of one's feeling regarding the ability to control what happens in the person's life. In the case of a worker, high locus of control would suggest that the individual feels powerful over the working environment and work success or failure on a day-to-day basis. We would expect that a feeling of control would make one more future-oriented.

Hypothesis 7: There is a positive relationship between Locus of Control and FTP.

Self-esteem infers positive feelings about oneself. Again, we expect a positive attitude to translate into a stronger future orientation.

Hypothesis 8: There is a positive relationship between Self-Esteem and FTP.

Several studies have found a significant relationship between FTP and Visioning Ability (Thoms \& Greenberger, 1998, Thoms \& Blasko, 1999). We replicated this research with two additional groups and expected to find the same relationship. 
Figure 1 Temporal Anchoring Model Of Future Time Perspective

Dynamic

Temporal

Factors

Stable

Temporal

Factors

\section{Figure 1 Temporal Anchoring Model Of Future Time Perspective}

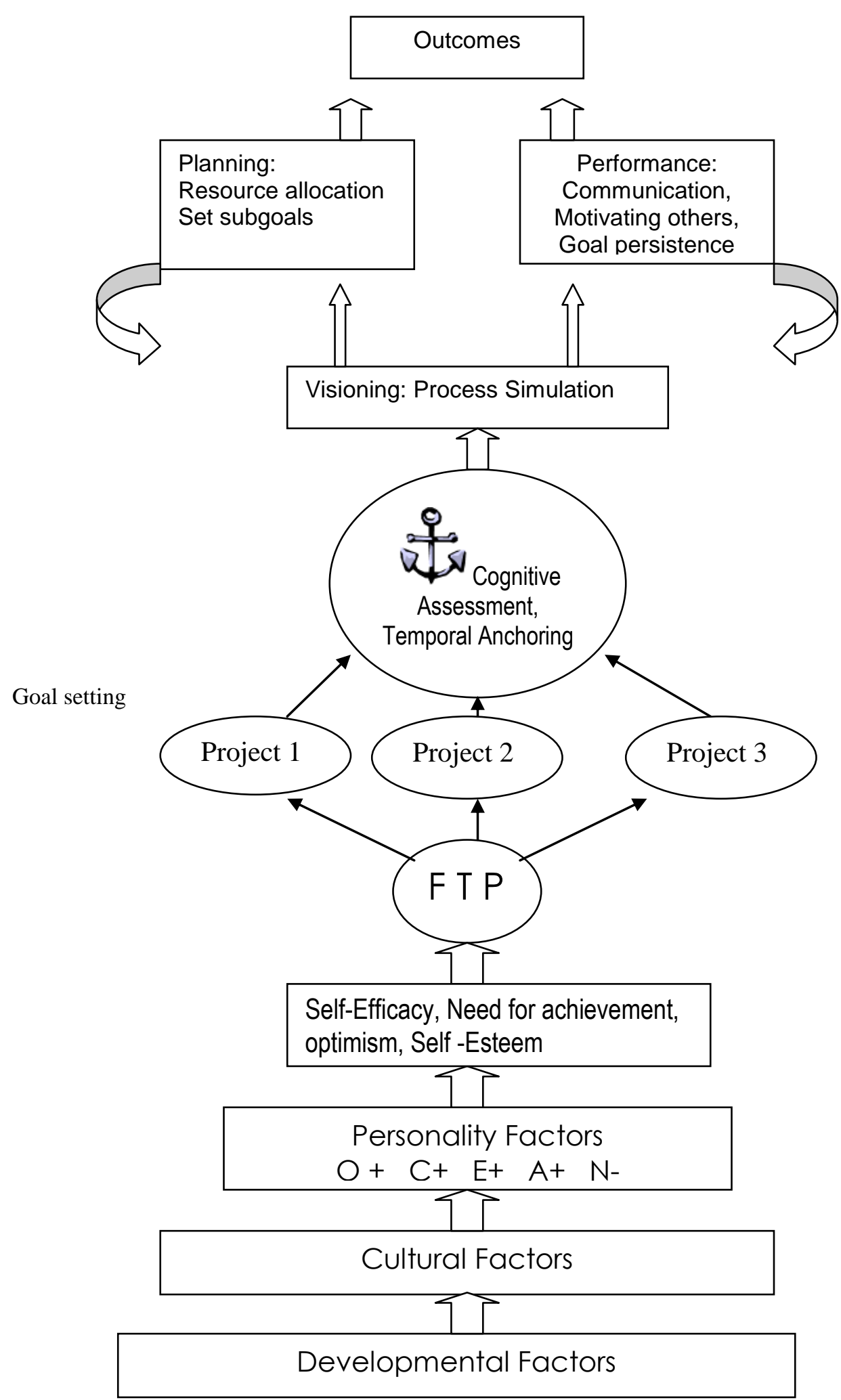


Hypothesis 9: There is a positive relationship between Visioning Ability and FTP.

In addition, the model suggests that FTP will relate to certain types of organizational behavior including persistence toward goals and performance. Since we believe that FTP serves as a cognitive anchor and has motivational effects, we expect that those who are higher in FTP will also have higher persistence toward goals and better outcomes.

Hypothesis 10: There is a positive relationship between Persistence toward Goals and FTP, and between measures of work performance and FTP.

Finally, we expect that because FTP is not a stable personality trait, we believe that it can be increased. If an individual is placed in a situation where the future, planning, strategy, and visioning are taught, FTP may also rise.

Hypothesis 11: FTP will increase following a training program on skills that are future oriented like vision creation and strategic planning.

We used three distinct sets of participants to test parts of the model. We began by testing the relationships between FTP and personality dimensions and related traits. This was done with workers in a manufacturing setting. We then tested the relationship between FTP and some additional personality variables and measures of behavior with a large group of student leaders at colleges from around the country. Finally, we used a small group of students to examine the relationship between FTP, visioning ability, and performance in a course. The three data sets and the methodology used with each are described below. The report on the results of the analysis of Data Sets 1 and 2 have been merged. Since Data Set 3 was used to look at how FTP relates to visioning ability and course performance, the rationale is explained as part of the methodology section for Data Set 3.

\section{Method - Data Set 1}

Participants and Procedure The first set of data was gathered in a small manufacturing company located in the Midwest. The manufacturing manager sent a memo inviting the 275 workers to attend one of a series of meetings. At these meetings, a company representative introduced one of the researchers, encouraged workers to participate in the study, and then left the meeting room. The university researcher explained the survey instrument and gave a general explanation of the study. The workers had the option to participate in the research, leave the room, or stay in the room and relax. The company provided refreshments and the time was paid. The participants were primarily white (96\%) and male (90\%), and averaged 42 years of age and 17 years with the company.

Measures The participants completed a questionnaire that measured FTP, the Big Five personality dimensions, Self-esteem, Need for Achievement, and Locus of Control. All measures used a Likert scale. FTP was measured using Daltrey's (1982) Future Time Perspective Test. We used 14 items from the original scale. A factor analysis using Principal Component Analysis indicated that the items loaded on one factor that explained $27 \%$ of the variance. The Cronbach Alpha measure of internal reliability was good at .77 .

The NEO-FFI (Costa, 1992), a 60-item short version of Costa and McCrae's (1992) NEO-PI was used to measure Conscientiousness, Extraversion, Neuroticism, Agreeableness and Openness. This instrument is one of the most widely used measures of the Big Five personality dimensions (Schmit, 1993). Each personality dimension is assessed using 12 items. The item responses are coded on five-point Likert scales ranging from Strongly Disagree (1) to Strongly Agree (5). This instrument has been shown to have high internal consistency reliability in previous research: 0.84 for Conscientiousness, 0.79 for Extraversion, 0.89 for Neuroticism, 0.74 for Agreeableness, and 0.76 for Openness (Schmit \& Ryan, 1993).

To measure self-esteem, we used the Rosenberg (1965) Self-esteem Scale. Need for achievement was measured using the Personality Research Form (PRF), Form E from Sigma Assessment Systems, Inc. We used the short form of the J.B. Rotter, Internal-External Locus of Control scale (Andrisani \& Nestel, 1976). 


\section{Method - Data Set 2}

Participants and procedures Participants in a weeklong leadership training program were asked to complete questionnaires. The training program was done at various locations around the United States throughout the summer months. Participants were college leaders and 54\% were male. The average age of the participants was 20 years. The ethnic composition of the sample was 68\% white Americans, $10 \%$ African Americans, $10 \%$ Hispanics, and 5\% Asian Americans. Six percent identified themselves as mixed race or Other. The trainees were approached by the administrators of the training program on the first day and asked to complete the questionnaire. The program included training on leadership vision, interpersonal skills, communication skills, strategic planning, and teamwork. At the end of the training during the first summer, participants were asked to complete a second questionnaire.

Measures The questionnaires used with Data Set 2 measured FTP using the 14-item version of Daltrey's (1982) scale, Optimism, and Visioning Ability. Optimism is a construct that indicates the personal optimism with which people approach common situations. The 48-item Attributional Style Questionnaire (Peterson, Semmel, von Baeyer, Abramson, Metalsky, \& Seligman, 1982) was used to measure Optimism. Visioning ability was measured with a scale developed by Thoms and Blasko (1999).

\section{Results of the Analysis of Data Sets 1 and 2}

See Table 1 for all of the correlations of the measured variables with FTP. The results supported the proposed relationships in the hypothesized directions.

Table 1 Correlations With Future Time Perspective

\begin{tabular}{lccc}
\hline Variable & Data Set 1 & Data Set 2 & Data Set 3 \\
\hline Mean & 3.54 & 4.00 & 3.96 \\
SD & .50 & .60 & .51 \\
\hline
\end{tabular}

Big Five Dimensions

$\begin{array}{lr}\text { Neuroticism } & -.34 * * * \\ \text { Extroversion } & .53^{* * *} \\ \text { Openness } & .32^{* * *} \\ \text { Conscientiousness } & .36^{* * *} \\ \text { Agreeableness } & .42^{* * *} \\ \text { elf-esteem } & .45^{* * *} \\ \text { eed for Achievement } & .49^{* * *} \\ \text { ocus of Control } & .30^{* * *}\end{array}$

Optimism $\quad .39^{*}$

Visioning Ability $\quad .17 * * *$

Persistence toward goals $\quad .26^{* * *}$

Tangible results $.14^{*}$

Organizational improvements $\quad .25^{*}$

Course grade $\quad .20 \mathrm{~ns}$

Project grade $\quad .25(\mathrm{p}<.07)$

\begin{tabular}{lll}
\hline $\mathrm{N}=$ & 264 & 411 \\
Response rate & $96 \%$ & $90 \%$
\end{tabular}

$* \mathrm{p}<.05, * * \mathrm{p}<.01, * * * \mathrm{p}<.001$ 
In addition, we compared levels of FTP, Optimism, and Visioning Ability in Data Set 2 from the beginning to the end of the training program. We expected to find that FTP and Visioning Ability are malleable and would increase during an intensive training program focused on future-oriented issues like vision and strategy. We did not expect Optimism to increase since the training did not attempt to manipulate that construct. Table 2 shows the results of that analysis. Visioning ability increased substantially during training. FTP also showed a statistically significant increase although the mean changes were quite small.

Table 2 Comparison of Variable Change Pre to Post Training

\begin{tabular}{|c|c|c|c|c|c|}
\hline & \multicolumn{2}{|c|}{ Beginning } & \multirow{2}{*}{$\begin{array}{l}\text { Ending } \\
\quad \text { Mean }\end{array}$} & \multirow[b]{2}{*}{ SD } & \multirow[t]{2}{*}{ t-value } \\
\hline & Mean & SD & & & \\
\hline \multicolumn{6}{|l|}{ Future Time } \\
\hline Perspective & 4.00 & .60 & 4.08 & .54 & $2.50 *$ \\
\hline Optimism & 3.19 & 3.28 & 3.40 & 3.28 & 1.48 \\
\hline Visioning Ability & 3.69 & .65 & 4.14 & .72 & $12.32 * *$ \\
\hline
\end{tabular}

Finally, we compared FTP with organizational behavior with the participants in Data Set 2. A questionnaire was sent to them three months after the training ended. They were asked to evaluate the leadership training that they received. In addition, we asked them to rate their behavior on three leadership-related behaviors and found that FTP was significantly correlated with all three. The post-training behavior that we examined was: persistence toward goals, tangible results, and organizational improvements.

\section{Introduction and Method - Data Set 3}

Mental simulations have been shown to improve performance on a variety of tasks, but one critical variable seems to be that the simulation involves imagining not just the end point or goal state in the future, but also the process whereby one gets to the goal (Taylor et al., 1998). For example, when students were asked to imagine a goal such as receiving a high grade on an exam, they showed no improvement in comparison to a control group. However, when students were asked to spend a few minutes each day imagining the process they needed to take to reach the goal, their performance improves. The process simulation seems to reduce the planning fallacy and encourage students to spend more time studying for the exam. One question that has received little attention is whether there would be a relationship between individual differences in visioning ability and actual performance when using a process simulation technique.

In this study, we recruited 55 college students from three undergraduate classes. The students were mostly traditional college age and were $90 \%$ white and $60 \%$ female. We first asked them to complete several questionnaires including the visioning ability scale and a measure of future time perspective. Students were trained during a 40-minute session in process simulation techniques. They were then asked to spend a few minutes each day imagining working on the steps of a major course project that was due six weeks later. The course project required teamwork and complex problem solving. Students kept a data sheet to record the time and date of each simulation. Fifty-one students reported completing the simulations and completed their project successfully. Based on previous work, we should see a positive correlation between visioning ability and future time perspective. We wondered 
whether actual performance, operationalized as project grades, would be more closely related to FTP or visioning ability. According to our model, a tendency to orient towards the future is a prerequisite to successful visioning. Higher future time perspective will allow one to create and maintain a more vivid and detailed vision of a future goal that, in turn, motivates the individual to work toward that goal. Therefore we should see a positive correlation between visioning ability and FTP, a positive correlation between Visioning ability and performance (project grades), but little relationship between FTP and grades.

\section{Results from the Analysis of Data Set 3}

As expected there was a correlation between future time perspective and visioning ability, $\underline{\mathrm{r}}=.73, \underline{\mathrm{p}}<.001$. Visioning ability, as assessed at the beginning of the class, was related to both the project grade, $\underline{\mathrm{r}}=.37, \mathrm{p}<.01$, and the overall course grade, $\underline{r}=.28, \underline{p}<.05$. However, future time perspective was not directly related to the course grade $\underline{\mathrm{r}}=.20, \underline{\mathrm{p}}=.15$, and was only marginally related to the project grade $\underline{\mathrm{r}}=.25, \underline{\mathrm{p}}=.07$. These findings are consistent with other studies finding a relationship between FTP and visioning ability, and between visioning ability and performance. It seems that in the case of project performance, future time perspective was indirectly related to performance through the use of visioning (mental simulation) of the steps/process needed to complete the project.

\section{Discussion}

Future Time Perspective is a potentially useful construct that has not been fully explored and studied in the organizational literature. Partial tests of the proposed model suggest that FTP is related to the Big Five personality dimensions, optimism, locus of control, need for achievement, and self esteem. In addition, it is correlated with visioning ability and with some organizational behaviors. More importantly, it appears that FTP can be manipulated through training. FTP has relatively stable side that is based on personality, culture and developmental stage, but it also has a more volitional and dynamic side that is responsive to situational needs.

Obviously, more empirical work must be done to further test this model. The path through which these many variables operate should be investigated using a sophisticated path analysis and a large-scale data set that includes all of the same variables from the same participants. In addition, more behavioral and outcome measures should be included. In our data analysis, FTP was found to be uni-dimensional. However, each of the scales we used was originally designed to be multi-factoral. Daltrey (1982) found hers to be uni-dimensional, but Bird and Jordan (1988) found five factors. It is necessary to use a larger group of participants and run another factor analysis. If multiple factors emerge, each factor's specific role in predicting skills, abilities, behaviors, and organizational outcomes should be examined. New techniques need to be developed to capture the stable and dynamic aspects of FTP.

Much work has been done examining the role of FTP and leadership, particularly in the area of organizational vision. However, one angle that has not been explored is how varying time perspectives within an organization may clash and derail a leader's vision and planning. For example, what if a leader has high FTP, but key followers (e.g. other senior executives) do not? Will the leader's vision influence the organization? Will planning take place? Will changes be implemented? In other words, whose temporal anchor will determine the strategic direction (or lack thereof)?

Research has demonstrated that goal setting is an effective motivational tool (Locke \& Latham, 1990). Might FTP explain why many people do not use goal setting, either personally or professionally? If FTP serves as a temporal anchor and goals are set with the future in mind, we might expect that people with low FTP would not be as likely to set goals or to use them if a manager assigns them. It appears that persistence toward goals will also be affected depending on one's FTP and the time span of the goal. More work must be done. This perceived lack of goal setting could also be due to two things we've discussed 1) Perhaps some of them are setting goals but are ineffective at it because they are using end point simulations instead of processing simulations. 2) Perhaps some are prioritizing goals differently --they are focusing on emotion goals instead of knowledge goals. In the organizational setting this could be seen as lack of goal setting. 
If future research supports the model of the role that FTP plays in organizational behavior, managers will be given new opportunities to enhance the direction, intensity, and persistence of work effort by subordinates. The most obvious, and tempting, application would be to hire new employees who have high FTP or who are very optimistic. The opposite approach would be to avoid hiring or promoting past-oriented or very pessimistic people in an organization. That may not be ethical or even practical in this time of low unemployment rates. What is more realistic would be to engage in activities that might increase the FTP of subordinates. One exercise that might be helpful would be to ask subordinates to imagine themselves engaged in the process of completing a task or project in the future. This would also include things like goal setting, sharing an organizational vision, working to make them more optimistic, and encouraging mental rehearsal and visualization of processes involved in projects and other assignments. Maybe what we want to do is work with the more dynamic aspect of FTP and encourage managers to understand the power of cognitive anchoring so that they can develop an appropriate time perspective for each project.

According to Taylor et al., (1998) mental simulation provides a window on the future by enabling people to envision their future goals and then create plans and strategies to bring those goals to fruition. Therefore, one's future time perspective becomes a cognitive anchor point that sets the framework for each new life project. It is now up to researchers to test and share implications for organizational applications.

\section{References}

1. Alvos, L., Gregson, R. A. M., \& Ross, M. W. 1993. "Future time perspective in current and previous injecting drug users". Drug and Alcohol Dependence, 31: 193-197.

2. Andrisani, P. J., \& Nestel, G. 1976. "Internal-External Control as contributor to and outcome of work experience". Journal of Applied Psychology, 61: 156-165.

3. Barrick, M. R., \& Mount, M.K. 1991. The Big Five personality dimensions and job performance: A metaanalysis. Personnel Psychology, 44: 1-23.

4. Barrick, M. R., \& Mount, M. K. 1993. Autonomy as a moderator of the relationships between the Big Five personality dimensions and job performance. Journal of Applied Psychology, 78: 111-118.

5. Bergius, R. 1957. Formen des Zukunftserlebens. München: Johann Ambrosius Barth.

6. Bird, B. J., \& Jordan, R. S. 1988. "Future time perspective: Scale development for organizational research". Working paper, Case Western Reserve University, Cleveland, OH.

7. Bluedorn, A. C. 1986. "Primary rhythms, information processing and planning: Directions for a new temporal technology". Paper presented at the meeting of the International Society for the Study of Time, Devon, U.K.

8. Bluedorn, A. C., Kaufman, C. F., \& Lane, P. M. 1992. How many things to you like to do at once? An introduction to monochromic and polychronic time. Academy of Management Executive, 6: 17-26.

9. Bucy, J. F. 1987. "Stratified systems theory and its implications for entrepreneurship". Paper presented at the annual meeting of the Academy of Management, New Orleans.

10. Burke, C. G. 1986. "Stratified systems theory: A time-based theory of organization". Paper presented at the annual meeting of the Academy of Management, Chicago.

11. Carstensen, L. L., \& Lang, F. 1997. "Social support in context and as context: Comments on social support and the maintenance of competence in old age". In S. Willis \& K. W. Schaie (Eds.), Societal mechanisms for maintaining competence in old age: 207-222. New York: Springer.

12. Carstensen, L. L., Isaacowitz, \& Charles, S. T. 1999. Taking time seriously: A theory of socioemotional selectivity. American Psychologist, 54: 165-181.

13. Clark, P. 1985. "A review of the theories of time and structure for organizational sociology". Research in the Sociology of Organizations, 4: 35-79.

14. Coren, S., \& Girgus, J. S. 1978. "Seeing is deceiving: The psychology of visual illusions". Hillsdale, NJ: Lawrence Erlbaum.

15. Costa, P. T., Jr., \& McCrae, R. R. 1992. Personality in adulthood: A six-year longitudinal study of selfreports and spouse ratings on the NEO Personality Inventory. Journal of Personality and Social Psychology, 54: 853-863. 
16. Daltrey, M. H. 1982. "The development and evaluation of a future time perspective instrument". Unpublished doctoral dissertation, University of Colorado, Boulder.

17. Daltrey, M. H., \& Langer, P. 1984. "Development and evaluation of a measure of future time perspective". Perceptual and Motor Skills, 58: 719-725.

18. Das, T. K. 1986. "The subjective side of strategy making: Future orientations and perceptions of executives". New York: Praeger.

19. Das, T. K. 1991. Time: The hidden dimension in strategic planning. Long Range Planning, 24: 49-57.

20. Friedman, W. 1990. About time: Inventing the fourth dimension. Cambridge, MA: MIT.

21. Goldberg, L. R. 1990. An alternative "description of personality": The Big Five factor structure. Journal of Personality and Social Psychology, 59: 1216-1229.

22. Goodman, R. A. 1975. Environmental knowledge and organizational time horizon: Some functions and dysfunctions. Human Relations, 26: 215-226.

23. Jaques, E. 1976. A general theory of bureaucracy. London: Heinemann.

24. Jaques, E. 1982. "The form of time". New York: Crane Russak.

25. Judge, T. A., Higgins, C. A., Thoresen, C. J., \& Barrick, M. R. 1999. The Big Five personality traits, general mental ability, and career success across the life span. Personnel Psychology, 52: 621-652.

26. Kahneman, D. \& Tversky, A. 1979. "Intuitive predictions: Biases and corrective procedures". TIMS Studies in Management Science, 12: 313-327.

27. Keough, K. A., Zimbardo, P. G. \& Boyd, J. N. 1999. Who's smoking drinking and using drugs? Time perspective as a predictor of substance abuse. Basic and applied Social Psychology, 21: 149-164

28. Knapp, R. H., \& Garbutt, J. T. 1958. Time imagery and the achievement motive. Journal of Personality, 26: $424-434$.

29. Lam, H., Schmidt, R. W., \& Trommsdorff, G. 1976. Sex and social class as determinants of future orientation (time perspective) in adolescents. Journal of Personality and Social Psychology, 34: 317-326.

30. Lens, W. 1986. "Goal setting, future time perspective, and strength of motivation". Paper presented at the International Congress of Applied Psychology.

31. Levine, R. 1997. "A geography of time: The temporal misadventures of a social psychologist". New York: Basic Books.

32. Lewin, K. 1935. "Field theory of learning". Yearbook of the National Society for the Study of Education, 41: 215-242.

33. Locke, E. A., \& Latham, G. P. 1990. "A theory of goal setting \& task performance". Englewood Cliffs, NJ: Prentice Hall.

34. Mann, H., Siegler, M., \& Osmond, H. 1968. The many worlds of time. The Journal of Analytical Psychology, 13: 33-56.

35. McCrae, R. R., \& Costa, P. T., Jr. 1997. Personality trait structure as a human universal. American Psychologist, 52: 509-516.

36. McCrae, R. R., \& John, O. P. 1992. An introduction to the five-factor model and its applications. Journal of Personality, 60: 175-215.

37. McGrath, J. E. 1988. "The social psychology of time: New perspectives". Newbury Park CA: Sage Publishers.

38. Nuttin, J., \& Lens, W. 1985. "Future time perspective and motivation: Theory and research method". Leuven \& Hillsdale, NJ: Leuven University Press \& Erlbaum.

39. Nuttin, J., Lens, W., Van Calster, K., \& De Volder, M. 1979. La perspective temporelle dans le comportement humain. In P. Fraisse (ed.) Du temps biologique au Temps Psychologique: 307-363. Paris: Presses Universitaires de France.

40. Peterson, D., Buchanan, G. M., \& Seligman, M. E. P. 1995. Explanatory style: History and evolution of the field. In G. M. Buchanan \& M. E. P. Seligman (Eds.). Explanatory Style: 1-20. Hillsdale, NJ: Lawrence Erlbaum Associates.

41. Pulver, A., Allik, J., Pulkkinen, L., \& Hamalainen, M. 1995. A Big Five personality inventory in two nonIndo-European languages. European Journal of Personality, 9: 109-124.

42. Richardson, A. 1994. "Individual differences in imaging: Their measurement, origins, and consequences". Amityville, NY: Baywood.

43. Rosenberg, M. 1965. "Society and the adolescent self image". Princeton, NJ: Princeton University Press. 
44. Salgado, J. F. 1997. The five factor model of personality and job performance in the European Community. Journal of Applied Psychology, 82: 30-43.

45. Schmit, M. J., \& Ryan, A. M. 1993. The Big Five in personnel selection: Factor structure in applicant and non-applicant populations. Journal of Applied Psychology, 87: 966-974.

46. Seijts, G. H. 1998. The importance of future time perspective in theories of work motivation. The Journal of Psychology, 132: 154-168.

47. Seligman, M. E. P. 1990. "Learned optimism". New York: Knopf.

48. Slife, B. D. 1993. "Time and psychological explanation”. Albany, NY: SUNY Press.

49. Spadone, R. A. 1992. Internal-external control and temporal orientation among Southeast Asians and white Americans. American Journal of Occupational Therapy, 46: 713-719.

50. Taylor, S. E., Pham, L., B., Rivkin, I. D. and Armor, D. A. 1998. Harnessing the imagination: mental simulation, self-regulation, and coping. American Psychologist, 53: 429-439.

51. Thoms, P., \& Blasko, D. G. 1999. Preliminary validation of a visioning ability scale. Psychological Reports, 85: 105-113.

52. Thoms, P., \& Greenberger, D. B. 1998. A test of vision training and potential antecedents to leaders' visioning ability. Human Resource Development Quarterly, 9: 3-19.

53. Thoms, P., \& Greenberger, D. B. 1995. The relationship between leadership and time orientation. Journal of Management Inquiry, 4: 272-292.

54. Thoms, P., \& Govekar, M. A. 1997. "Vision is in the eyes of the leader: A control theory model explaining organizational vision”. OD Practitioner, 29: 15-24.

55. Thoms, P., \& Pinto, J. K. 1999. Project leadership: A question of timing. Project Management Journal. 30: $19-26$.

56. Tokar, D. M., Fischer, A. R., \& Subich, L. M. 1998. Personality and vocational behavior: A selective review of the literature, 1993-1997. Journal of Vocational Behavior, 53: 115-153.

57. Tversky, A., \& Kahneman, D. 1982. "Judgment under uncertainty: Heuristics and biases". In D. Kahneman, P. Solvic, \& A. Tvesky (Eds.) Judgment under uncertainty: heuristics and biases: 3-20. New York: Cambridge University Press.

58. Vella, C. J. 1977. Temporal perspective: Validation and psycho-social correlates among college students. Unpublished doctoral dissertation, University of California, Berkeley.

59. Wallace, M. 1956. Future time perspective in schizophrenia. Journal of Abnormal and Social Psychology, 52: 240-245.

60. Wallace, M., \& Rabin, A. I. 1960. Temporal experience. Psychological Bulletin, 57: 213-236.

61. Weick, K. E. 1979. The social psychology of organizing. Reading, MA: Addison-Wesley.

62. Zalenski, E. H. Levey-Thors, C. \& Schiaffinor, K. M. 1998. Coping mechanisms, stress, social support, and health problems in college students. Applied Developmental Science. 2: 127-137. 